\title{
Properties of Hydrochloric Chitosan Solutions Modified With Nano- Calcium Phosphate Complex
}

Pighinelli L*, Guimaraes MF and Paz RL

Universidade Luterana do rBasil, Brazil

\begin{abstract}
Nature itself uses materials like cellulose to provide the structure of plants, chitin as the exoskeleton of several insects and molluscs, collagen for mechanical support in connective tissues and so on. At present, the socioeconomic situation of the modern world has raised the interest in renewable materials to use in regenerative medicine. The composition of Chitosan and/or Calcium Phosphates are derived from the junction of two or more different materials, containing organic and inorganic materials, including characteristics of both materials like bioactivity and biodegradability and biocompatibility with human tissues.

The chemical characteristics of chitosan and nano B-TCP / HAp complex showed that both of the components organic and inorganic exist in the material showing a good stability of the nano-ceramic formation in the chitosan salt solutions. All complex by Zeta-Potential, showing also a new method of preparations nanoparticles of calcium phosphates in chitosan solution from commercial calcium phosphates in micro size. These materials can be used in future for medical applications as a base for scaffolds production and as implants in regenerative medicine.
\end{abstract}

Keywords: Chitosan salt; Chitosan; Nano calcium phosphate; Functional biopolymer; Medical applications

\section{Introduction}

Hard tissue of the human body is very important. The skeletal system provides support and gives shape to the body and provides a network for all soft tissues. The most common problems with hard tissues are bone fractures, defects or diseases in addition other various problems which need to be cured. Bone consists of $69 \%$ calcium phosphate (mainly hydroxyapatite), $21 \%$ collagen, $9 \%$ water and $1 \%$ other constituents. It has a composite nature which is built up of mainly ceramic (hydroxyapatite) and polymer (collagen), with a complex hierarchical microstructure very difficult to imitate which gives most of the superior mechanical properties to bone [1-5].

Biomaterials as an artificial bone are classified into surface-active materials such as hydroxyapatite (HAp), and resorbable materials such as $ß$-Tricalcium Phosphate ( $ß-\mathrm{TCP})$ and bioactive and biodegradable material as a chitosan and its derivatives [6,7]. The composition of biomaterials as a ceramics, polymers and/or composite materials, with all advantages and drawbacks, are developed to be used for bone problems. When all these properties of polymers, ceramics are considered producing composite materials have a reasonable approach $[2]$.

Surface-active biomaterials as a calcium phosphates bind to bone through an apatite layer formed on the material surface after implantation. It is assumed that the velocity of layer formation correlates with bioactivity. However, how bioactivity affects the formation of the apatite layer, it has not been made clear whether the apatite layer can be formed only under the influence of the bone tissue [8-10].

Calcium phosphate constitute a major family of inorganic materials currently in use in dental and orthopedic reconstructive medicine, specifically, Hydroxyapatite (HAp) and ß-Tricalcium Phosphate (B-TCP) were developed as bio ceramics in the early 1980s and nowadays are the most common calcium phosphates used in medical applications [8]. Despite their relative importance, both ceramics show a number of drawbacks that reduce their clinical performance. The biodegradation of HAp in physiological environments is too low to achieve the optimal formation of bone tissue [9]. On the other hand,
ß-TCP shows fast release of $\mathrm{Ca}^{2+}$ and $\mathrm{PO}_{4}^{3-}$ ions when exposed to physiological fluids and could be considered as bioactive [10].

Tri-calcium phosphate is called a resorbable ceramic, and it is believed that it binds to bone and is then resorbed and replaced by bone. It has been reported that the bioresorbability is due to dissolution and phagocytosis. It has been considered that B-TCP makes contact with bone directly, suggesting mainly mechanical bonding $[9,10]$.

Tri-calcium phosphate ( $(B-\mathrm{TCP}), \mathrm{Ca}_{3}\left(\mathrm{PO}_{4}\right)_{2}$, and hydroxyapatite (HAp), $\mathrm{Ca}_{10}\left(\mathrm{PO}_{4}\right)_{6}(\mathrm{OH})_{2}$, are compounds with a high potential for bio applications. In particular, composites made of B-TCP and HAp, socalled biphasic calcium phosphates and/or ceramic, which combine the excellent bioactivity of HAp with the good bioresorbability of B-TCP, are interesting candidates for medical applications as, for example, materials for bone replacement [10-12]. The biological performance of biphasic mixtures with HAp and B-TCP is controlled by the dissolution profile of the mixture. Selecting the appropriate blend of both calcium phosphates, the mixture gradually dissolves in the physiological environment, releasing $\mathrm{Ca}^{2+}$ and $\mathrm{PO}_{4}^{3-}$ ions and inducing the bioactive behavior. The material that remains during dissolution acts as a template for the newly formed bone [9-11]. In the (Figure.1) shown the schematic illustration of the mechanism between chitosan and calcium/ phosphate ions.

Polyaminosaccharides, especially chitosan (poly $(\beta-(1,4)-2$-amino2 -deoxy-D-glucopiranose)) and its derivatives, are characterized by excellent biostimulation properties which facilitate reconstruction and

*Corresponding author: Pighinelli L, Campus Canoas, Av. Farroupilha, $\mathrm{n}^{\circ} 8001$ Bairro São José code. 92425-900. Canoas/RS, Brazil, Tel: +555130290090; Fax: +555134771313; E-mail: Ipighinelli@hotmail.com

Received August 12, 2015; Accepted September 10, 2015; Published September 17, 2015

Citation: Pighinelli L, Guimaraes MF, Paz RL (2015) Properties of Hydrochloric Chitosan Solutions Modified With Nano-Calcium Phosphate Complex. J Tissue Sci Eng 6: 155. doi:10.4172/2157-7552.1000155

Copyright: (c) 2015 Pighinelli L, et al. This is an open-access article distributed under the terms of the Creative Commons Attribution License, which permits unrestricted use, distribution, and reproduction in any medium, provided the original author and source are credited. 


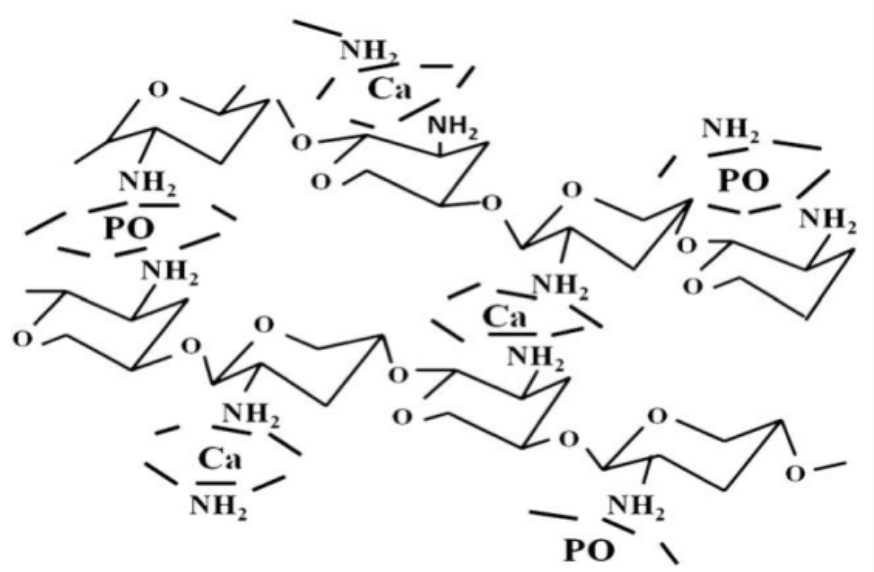

Figure 1: Schematic illustration of the mechanism between chitosan and calcium/phosphate ions [16].

vascularization of damage tissues, also compensate the shortcomings of cells components, nutrient flow, which are conductive for small scar forming [13]. This cationic property is the basis of many of the potential applications of chitosan that can be considered as a linear polyelectrolyte with a high charge density which can interact with negative charged surfaces, like proteins and anionic polysaccharides [14]. Chitosan exhibits a variety of physicochemical and biological properties, therefore it has found numerous applications in various fields such as waste and water treatment, agriculture, fabric and textiles, cosmetics, nutritional enhancement, and food processing. In addition to its lack of toxicity and allergenicity, its biocompatibility, biodegradability and bioactivity make it a very attractive substance for diverse applications as a biomaterial in pharmaceutical and medical fields [13,15-17]. To improve the suitability of chitosan and its derivatives for bone tissue engineering, the biocomposites of chitosan, ß-TCP and/or hydroxyapatite could be applied.

\section{Materials and Methods}

\section{Materials}

- Initial chitosan from Primex Co (Norway) trade name Chito Clear FG90 was used, characterized by: average molecular weight $\left(\mathrm{M}_{\mathrm{v}}\right)=342$ $\mathrm{kD}$, deacetylation degree $(\mathrm{DD})=82 \%$, ash content $=1.7 \%$, Moisture content $=5,58 \%$, Water retention value $43,45 \%$, Dynamic Viscosity $63,11 \mathrm{cP}$

- Tri-calcium phosphate ( $(\mathrm{T}-\mathrm{TCP}),\left(\mathrm{Ca}_{3}\left(\mathrm{Po}_{4}\right)_{2}\right)$ - Sigma Aldrich Lab., Germany

- Hydroxyapatite $\left.\mathrm{Ca}_{10}\left(\mathrm{Po}_{4}\right)_{6}(\mathrm{OH})_{2}\right)$ - Sigma Aldrich Lab., Germany

- Hydrochloric ac. $37,8 \%$ p.a., manufactured by Fluka.

\section{Methods}

Analytical methods for hydrochloric chitosan salt solution characterization:

a) The average molecular weight of chitosan was determined according to the viscometric method using an aq. solution of $0.1 \mathrm{M}$ sodium chloride, $0.2 \mathrm{M}$ acetc acid and $4.0 \mathrm{M}$ of urea, calculating $\mathrm{Mv}$ according to the Mark-Houwink's equation with $\mathrm{K}=8.93 \times 10^{-4}$ and $\mathrm{a}=0.71$. Standard SPR/BLF/05 b) The water retention value of chitosan (WRV) is determined by submerging $0.5 \mathrm{~g} \pm 0.0001 \mathrm{~g}$ of chitosan in $50 \mathrm{~cm}^{3}$ of distilled water. Next it is centrifuged for $10 \mathrm{~min}$ at $4000 \mathrm{rpm}$. The weight of the sample is determined after centrifuging $\left(\mathrm{m}_{1}\right)$ and after drying to constant weight after 20 hours at $105^{\circ} \mathrm{C} \pm 1^{\circ} \mathrm{C}\left(\mathrm{m}_{0}\right)$. The water retention value ( $\mathrm{WRV}, \%)$ is found from the equation: $\mathrm{WRV}=\frac{m_{1}-m_{0}}{m_{0}} \times 100$

c) Deacetylation degree of chitosan is determined by the potentiometric titration method using the first derivative UVspectrophotometry (DUVS). The concentration of chitosan solution is up to $100 \mathrm{~cm}^{3}$ with anhydrous acetic acid 0.0100 $\mathrm{M}$. The presence of D-glucosamine was corrected for by a reference curve for $\mathrm{N}$-acetyl-D-glucosamine. Therefore, we advocate DUVS to be used by the standard methods for routine determination of DD of chitosan.

d) Ash content in chitosan - the quartz crucible is heated in the furnace at $800^{\circ} \mathrm{C}$ to constant weight. After cooling to ambient temperature in the exsiccate, the crucible is weighed on the analytical balance. After preheating the chitosan sample is burned in the furnace at $800^{\circ} \mathrm{C}$ for about $3 \mathrm{~h}$, to the constant weight. After cooling to ambient temperature the burned sample is weighed.

e) Determination of polymer content in chitosan - approx. $5 \mathrm{~g} \pm$ $0.0001 \mathrm{~g}\left(\mathrm{~m}_{0}\right)$ of chitosan sample is placed in a laboratory dryer and dried at the temperature of $105^{\circ} \mathrm{C} \pm 1^{\circ} \mathrm{C}$ to constant weight $\left(\mathrm{m}_{1}\right)$. The polymer content $\left(\mathrm{S}_{\mathrm{m}}\right)$ is calculated from following equation: $\mathrm{S}_{\mathrm{m}}=\left(\mathrm{m}_{0}: \mathrm{m}_{1}\right) \times 100 \%$

f) Determination of dynamic viscosity by Brookfield method was performed using a Brookfield viscometer type cone - plate. $1 \%$ solution of chitosan in $1 \%$ acetic acid has been prepared. The Brookfield DV-II + Pro Viscometer measures fluid viscosity at given shear rates. Viscosity is a measure of fluid's resistance to flow.

The principal of operation of the DV-II+Pro is to drive a spindle (which is immersed in the test fluid) through a calibrated spring. The viscous drag of the fluid against the spindle is measured by the spring deflection. Spring deflection is measured with rotary transducer. The measurement range of a DV-II+Pro (in centipoise - $\mathrm{cP}$ ) is determined by the rotational speed of the spindle, the size and shape of the spindle, the container the spindle is rotating in, and the full scale torque of the calibrated spring.

g) The moisture content in chitosan is determined by a weight method drying samples to constant weight at temperature of $105 \pm 1{ }^{\circ} \mathrm{C}$.

Preparation of hydrochloric chitosan/B-TCP complex solution: The complex solution was prepared according to a method elaborated in the Institute of Biopolymers and Chemical Fibers, Poland. [16,18].

Preparation of hydrochloric chitosan/ B-TCP and HAp complex solution: Chitosan/B-TCP/HAp complex solution was prepared according to a method elaborated in the Institute of Biopolymers and Chemical Fibers, Poland [17,18].

Elaboration of the quantitative and qualitative chitosan solutions: The main objective of this study was to elaborate qualitative and quantitative composition of MCCh/ B-TCP complex with HAp to obtain a homogenous hydrochloric chitosan solution with nano 
Citation: Pighinelli L, Guimaraes MF, Paz RL (2015) Properties of Hydrochloric Chitosan Solutions Modified With Nano-Calcium Phosphate Complex. J Tissue Sci Eng 6: 155. doi:10.4172/2157-7552.1000155

ceramic. The quantitative and qualitative compositions of composite are given in Table 1 and 2.

Infrared Spectroscopy HAp and B-TCP powders: Infrared spectroscopy Fourier Transform (FTIR) is a non-destructive technique that was used to identify the functional groups through their chemical bonds, which generate a spectrum of infrared bands characteristic of each connection type. The infrared analysis was in the range of 500 to $4000 \mathrm{~cm}^{-1}$, resolution $4.0 \mathrm{~cm}^{-1}$ with a Spectrum Genesis Series. Samples were prepared for analysis with $\mathrm{KBr}$, in the form of tablets. To verify the presence of functional characteristic groups of $\mathrm{B}-\mathrm{TCP}$, HAp.

Determination of particles size in HAp and ß-TCP powders: The technique used was by laser particles size by Sympatec Hellos H1330, type BF (sympatec GmbH, Clausthal, Germany). The analysis was performed in collaboration Thuringian Institute of Textile and Plastics Research, Rudolstadt, Germany.

SEM study of the calcium phosphate powders: The particle size of commercial B-TCP and HAp powder, was observed using a scanning electron microscopy (SEM)-FEI Quanta 200, USA.

Determination of particles size and zeta potential of calcium phosphates in chitosan solution: The size of the particles of HAp, $\beta$-TCP and HAp/ $\beta$-TCP in chitosan solution was measured using a ZETASIZER 2000 (Malvern Instruments) apparatus.

\section{Results and Discussion}

\section{FTIR study}

FTIR of the calcium phosphate powders: The main peaks of energy vibration identified in the B-TCP, HAp powders are shown in the (Figure 1). The characteristic functional groups of orthophosphate $\left(\mathrm{PO}_{4}^{-3}\right)$, hydroxyl $(\mathrm{OH})^{-}$, phosphate $\left(\mathrm{HPO}_{4}^{-2}\right)$ the latter one in trace amount, shown characteristic peaks of calcium phosphates material. The presence of carbonate group was observed, in trace, in the commercial B-TCP and HAp material, that suggest in some commercial $B$-TCP and $\mathrm{HAp}$ the $\mathrm{CaO}$ and $\mathrm{Ca}(\mathrm{OH})$, are used to get an ideal stoichiometric relation between $\mathrm{Ca} / \mathrm{P}$ in the material and related with the preparation process of the samples that were prepare in atmosphere conditions with presence of carbon dioxide and air.

In the peaks of the $ß$-TCP powder, the absence of bands at $740(\mathrm{~cm}$ ${ }^{1}$ ) and an isolated band, $600 \mathrm{~cm}^{-1}$; characteristic of $\alpha$-TCP, indicating that the starting material is only composed of $B$-TCP, also shows a small amount of $\mathrm{CO}_{3}^{-2}$ in $1428 \mathrm{~cm}^{-1}$. This calcium phosphate is easily identified by presenting a broad band in $900-1200 \mathrm{~cm}^{-1}$; observed the

\begin{tabular}{|l|c|c|}
\hline \multicolumn{1}{|c|}{ POWDERS } & HAp & $\beta$-TCP \\
\hline Particles size $(90 \%),(\mu \mathrm{m})$ & 8,81 & 12,78 \\
\hline Particles size $(50 \%),(\mu \mathrm{m})$ & 3,16 & 4,48 \\
\hline Particles size $(10 \%),(\mu \mathrm{m})$ & 0,97 & 1,35 \\
\hline Superficial area $\left(\mathrm{cm}^{2} / \mathrm{g}\right)$ & $3,41 \mathrm{e}+04$ & $2,53 \mathrm{e}+04$ \\
\hline
\end{tabular}

Table 1: Particles size of commercial HAp and B-TCP.

\begin{tabular}{|c|c|c|c|c|}
\hline $\begin{array}{c}\text { Symbol of } \\
\text { samples }\end{array}$ & $\begin{array}{c}\text { Chitosan } \\
(\%)\end{array}$ & $\begin{array}{c}\text { B-TCP } \\
(\%)\end{array}$ & $\begin{array}{c}\mathrm{HAp} \\
(\%)\end{array}$ & $\begin{array}{c}\mathrm{HCl} \\
(\%)\end{array}$ \\
\hline Solution B & 2 & 2,0 & 0 & 0,9 \\
\hline Solution C & 2 & 0 & 0,5 & 0,9 \\
\hline $\begin{array}{c}\text { Blend B/C } \\
\text { 2:1 ratio }\end{array}$ & 2 & 2,0 & 0,5 & 0,9 \\
\hline
\end{tabular}

*Dry polymer content $2,0 \%$

Table 2: The formulations characteristic of hydrochloric chitosan solutions.

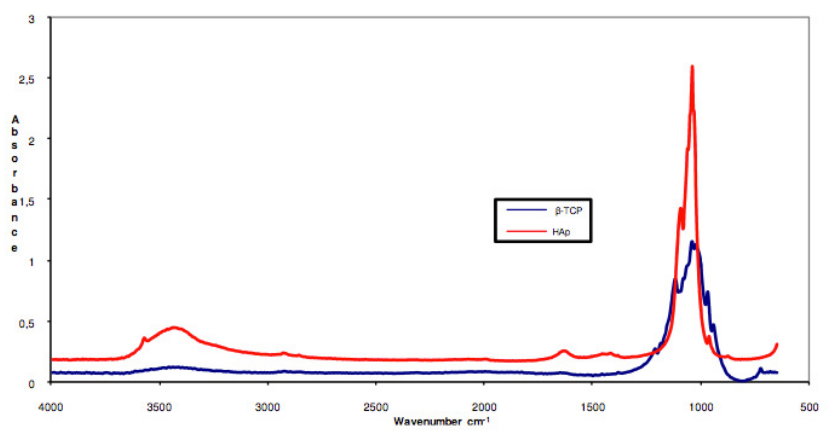

Figure 2: FTIR spectrum of the commercial HAp and $\beta$-TCP.
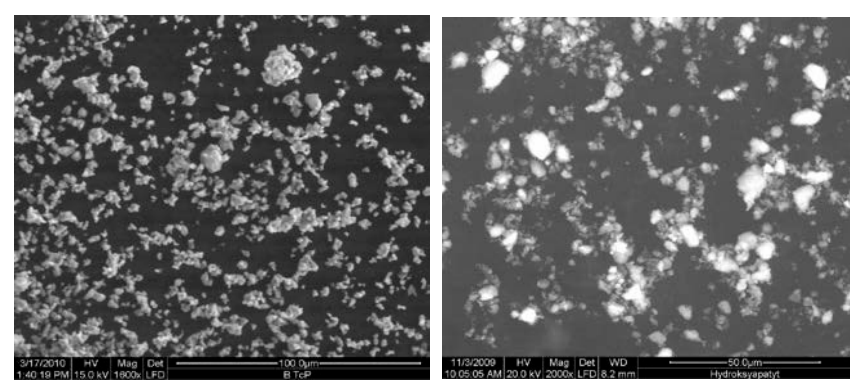

Figure 3: Showed the a) $\beta-T C P$ and b) Hap, respectively.

presence of the peak at $724 \mathrm{~cm}^{-1}$, characteristic of the symmetric mode (P-O-P) assigned to distortion of P-O. Since the peak at $1211 \mathrm{~cm}^{-1}$ is characteristic of a non-degenerate deformation of hydrogen groups $-\mathrm{OPO}{ }_{3},-\mathrm{H}, \mathrm{O}-\mathrm{PO}_{3}$, common ions $\mathrm{HPO}_{4}^{-2}$, the presence of this group may be a consequence of the interaction of water molecules in the structure [18-21] (Figure 2).

In the spectrum of the HAp sample, the peaks that are observed, Figure 1, $839\left(\mathrm{~cm}^{1}\right)$ that correspond to deformation modes of phosphate groups (O-P-H) bonds, associated with energy level and the kind of neighbourhood that are linked with the rotational type of the bond $\mathrm{O}-\mathrm{H}$. In $3570 \mathrm{~cm}^{-1}$ and $3464 \mathrm{~cm}^{-1}$ is observed also the $\mathrm{OH}^{-}$group peak, referring to the way they stretch. The band observed at $962 \mathrm{~cm}^{-1}$ of low intensity, corresponding to non-degenerate symmetric stretching of P-O bonds of phosphate groups. The bands 1040 and $1093\left(\mathrm{~cm}^{-1}\right)$ represent the asymmetric stretch modes, respectively, the P-O bonds of phosphate groups.

There is presence of water in the starting materials for the existence of peaks associated in the regions of $1590,1635\left(\mathrm{~cm}^{-1}\right)$ and the peaks around $3400 \mathrm{~cm}^{-1}$, suggesting the presence of water molecules adsorbed in the sample [18-21] (Figure 2).

\section{Determination of particles size in HAp and $B$-TCP powders}

The aim of this study was to determine the particle size and morphology of the commercial HAp and B-TCP in form of powder. The (Figure $3 \mathrm{a}$ and $3 \mathrm{~b}$ ) showed the $\mathrm{B}$-TCP and Hap, respectively.

Notice the morphologies of the powder differ in shape, the $B$-TCP powder is shown in the Figure $4 \mathrm{a}$, is more spherical that HAp powder (Figure 4b). Also the powders showed great ability to agglomeration and cluster formation, explained by a not homogenous charge distribution on the surfaces and high ability for water adsorption.

The analysis showed of particles size depends first on particle shape 


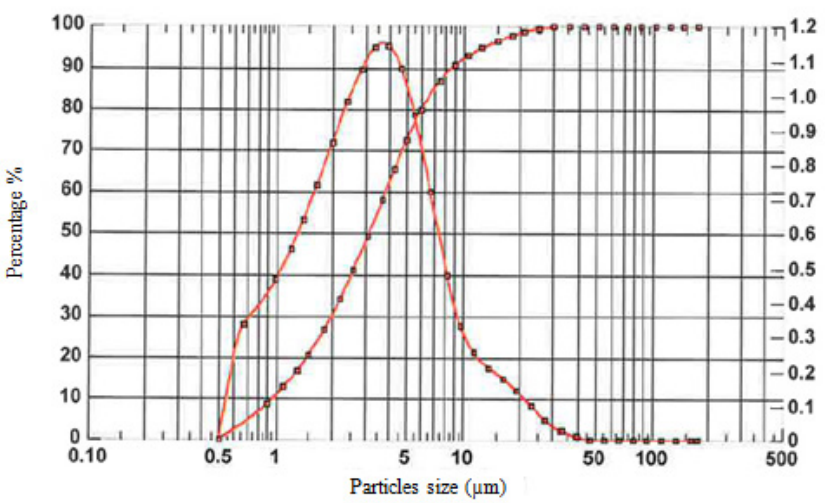

Figure 4a: Grain size and distribution of synthetic HAp powder.

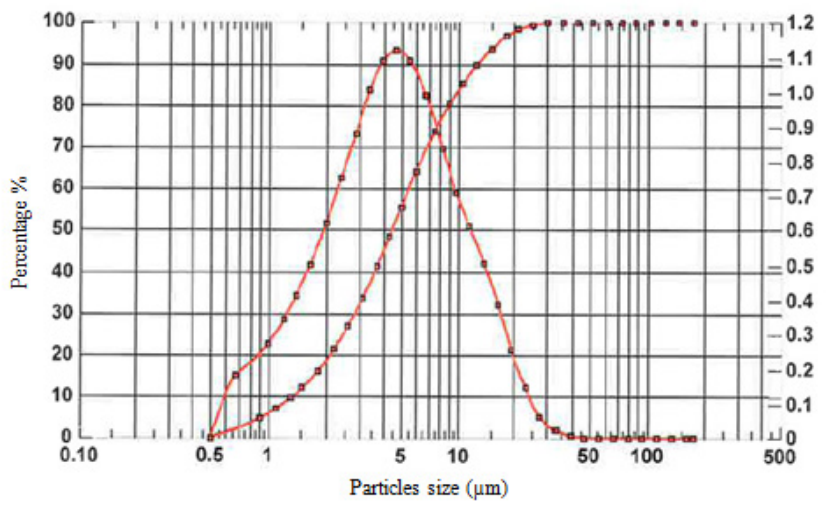

Figure 4b: Grain size and distribution of synthetic $\beta$-TCP powder.

(aspect relation). Most calculation models refer to ball-shaped bodies. The more the particles deviate from this model the more the deviation rises. Secondly, the broadness (width) of particle size distribution has an influence on the standard deviation using this method. In a case where this distribution covers only a narrow part, for instance 2 to 5 $\mu \mathrm{m}$, then the deviation is lower than $10 \%$.

However, the measurement itself is very precise. The measurement of the powders used in this research had procedure of three-times for each sample and receives deviations of results lower than $2 \%$, the samples of both powders had a range from 0.5 to $50 \mu \mathrm{m}$. The analysis showed a $B$-TCP grain size fits in the range 4.48.0-12.78 $\mu \mathrm{m}$ and grain size of HAp fits mainly in the range 3.16-8.81 $\mu \mathrm{m}$.

The particles size distribution graphics of the commercial calcium phosphate powders HAp and B-TCP used in this research are shown in the Figure $4 \mathrm{a}$ and $4 \mathrm{~b}$, respectively and the particles size are showed in (Table 1).

The measurements of particles size by laser particles size gave a specified surface area covered by each powder HAp is 3,41 e+04 $\mathrm{cm}^{2} / \mathrm{g}$ and $\mathrm{B}$-TCP $2,53 \mathrm{e}+04 \mathrm{~cm}^{2} / \mathrm{g}$. Also it was found around $10 \%$ of the calcium phosphate particles (HAp and B-TCP) was nano size that also indicate a faster and easier release of calcium and phosphate ions in physiological environmental with more homogenous distribution following the literature [22-24]. There are many factors related with the performance of the biocomposite for hard tissue regeneration that reflect in the preparation of suspension, mechanical properties and calcium and phosphate ions in the physiological environmental as a particles size, shape, particles distribution and ratio of inorganic part in the polymer matrix.

\section{Preparation of chitosan solutions containing $\beta$-TCP, HAp and HAp/ $\beta$-TCP}

The hydrochloric acid and nitric acid are the two best inorganic acids used to dissolve the apatites family; however the literature shows that the hydrochloric acid is already used to prepare biomaterials like scaffolds used in regenerative medicine. In the (Figure 5), the process of dissolution of the initial chitosan, using a solution of micro-particles of $\beta$-TCP dissolved with $0,9 \%$ of hydrochloric acid reduced the number of the particles of $\beta$-TCP to nano size, resulting in a clear solution of hydrochloric chitosan salt/ $\beta$-TCP in nano particles. The solution B was an aqueous $2.0 \mathrm{wt} \%$ solution of chitosan in $0.9 \mathrm{wt} \%$ solution of hydrochloric acid with a $2.0 \mathrm{wt} \%$ weight content of $\beta$-TCP nanoparticles.

In the Figure 6, showed that Hydroxyapatite is less soluble than $\beta$-TCP; this was apparent in the course of preparing solution $C$ when only a small amount of HAp dissolved while the majority appeared as an opalescent suspension. Solution $\mathrm{C}$ was a diluted aqueous 2.0 wt\% chitosan solution in $0.9 \mathrm{wt} \%$ hydrochloric acid containing HAp particles at a concentration of $0.5 \mathrm{wt} \%$ resulting in a chitosan hydrochloric solution contained HAp particles with a diameter of up to a few micrometres.

The Figure 7, shows that mixing of the chitosan solution containing HAp (solution C) with the chitosan solution containing $\beta$-TCP (solution B) in hydrochloric acid at a ratio of $2: 1$ provided adequate conditions for the dissolution of HAp. The dissolution of HAp in chitosan solution containing $\beta$-TCP, suggest strong ionic interaction between calcium phosphates creating a nano ceramic and with the amino groups of the chitosan.

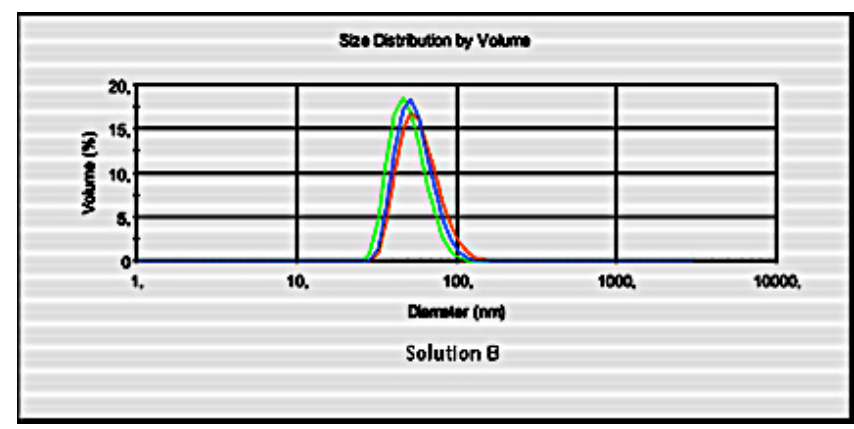

Figure 5: Particle size distribution of $\beta$-TCP in chitosan solution in hydrochloric acid.

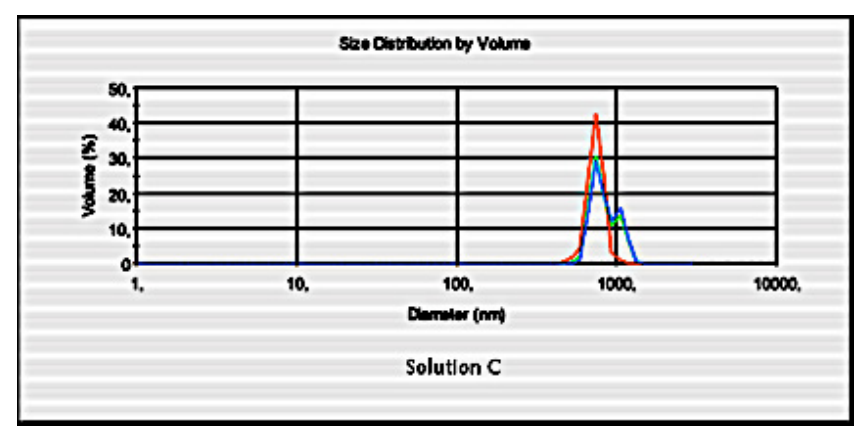

Figure 6: HAp particles in chitosan hydrochloric solution (solution C). 
Citation: Pighinelli L, Guimaraes MF, Paz RL (2015) Properties of Hydrochloric Chitosan Solutions Modified With Nano-Calcium Phosphate Complex. J Tissue Sci Eng 6: 155. doi:10.4172/2157-7552.1000155

Page 5 of 6

\begin{tabular}{|c|c|c|c|}
\hline Chitosan solution & $\begin{array}{c}\text { Range of particles size } \\
\mathrm{nm}\end{array}$ & $\begin{array}{c}\text { Size of fraction with highest content } \\
\mathrm{nm}\end{array}$ & $\begin{array}{c}\text { Percentage of volume } \\
\%\end{array}$ \\
\hline Solution B & $28.9-164.9$ & 65.2 & 11.5 \\
\hline Solution C & $417.3-1495$ & 745.4 & $43.0 \pm 2.3$ \\
\hline Blend of Solution B/C 2:1 Ratio & $12.8-58$ & 22.9 & $45.3 \pm 2.3$ \\
\hline
\end{tabular}

Table 3: Selected parameters of chitosan solutions containing HAp, $\beta$-TCP and HAp/ $\beta$-TCP.

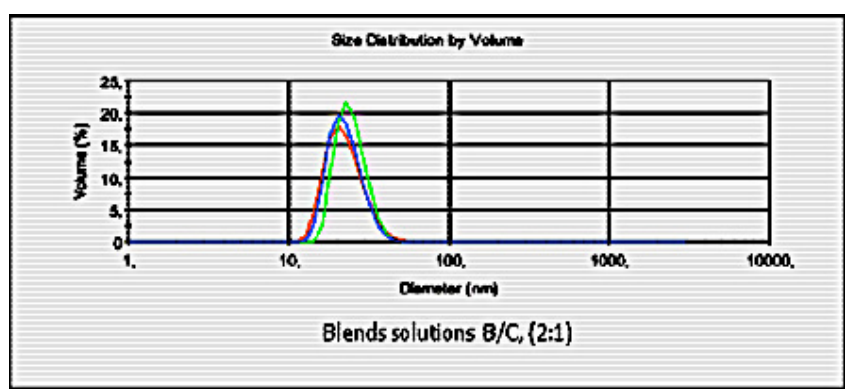

Figure 7: The HAp/ $\beta-T C P$ blend in chitosan (solution B/C).

The amount of free HAp not linked with the amino groups of the solution $\mathrm{C}$ probably dissolved in the hydrochloric acid in the solution $\mathrm{B}$, used in this experiment. During the blending of the HAp and $\beta$-TCP particle-containing chitosan solutions the HAp particles dissolved immediately resulting in a clear solution.

Comparing the images of the chitosan solutions in the Figure 7 , revealed that mixing the HAp and $\beta$-TCP containing chitosan solutions had a beneficial effect by the size of the nanoparticles within the range of 12.8-58.0 nm. The dissolution of HAp in chitosan solution and the mechanism of salts and amino acids upon the dissolution of HAp have been reported previously [17,25]. Table 3 showed the range of particles size of the solutions and the blend also the stability of the solution by Zeta Potential.

The calcium phosphate nanoparticles to the chitosan solutions resulted in a slight drop in the chitosan content, the Zeta Potential showed greater stability of the blend comparing with the solutions $B$ and $C$ that suggest a good interaction between HAp and $\beta$-TCP and the amino groups

\section{Conclusions}

1) The FTIR analysis showed a characteristic peak of B-TCP and HAp in the samples.

2) The morphologies of the powder differ in shape; the $B$-TCP powder is showed more spherical that HAp powder. Also the powders showed great ability to agglomeration and cluster formation, explained by a not homogenous charge distribution on the surfaces and high ability for water adsorption. Particles size of $B$-TCP range 4.48.0-12.78 $\mu \mathrm{m}$ and grain size of HAp fits mainly in the range $3.16-8.81 \mu \mathrm{m}$.

3) During the blending of the HAp and $\beta$-TCP particle-containing chitosan solutions the HAp particles dissolved immediately resulting in a clear solution shopping a greater stability and beneficial effect by the size of the nanoparticles within the range of $12.8-58.0 \mathrm{~nm}$.

4) In this work showed a novel method to obtain a chitosan solution with nano ceramic using a comercial HAp and $\beta$-TCP in micro size.

\section{Acknowledgement}

The authors received funding from the European Community's Seventh Framework Program [FP7/2007-2013] under grant agreement no. PITNGA-2008-214015

Analysis of the HAp, $\beta$-TCP particle size, X-Ray diffraction and in the composites $\mathrm{Ca}$ and phosphor content, was carried out using equipment provided by the TITK- Thuringian Institute of Textile and Plastics Research, Rudolstadt, Germany).

\section{References}

1. Pighinelli L, Kucharska M, WÃsniewska-Wrona M, Grucha ÅaB, BrzozaMalczewska K (2012) Biodegradation study of microcrystalline chitosan and microcrystalline chitosan/ $\hat{I}^{2}$-TCP complex composites. Int J Mol Sci 13: 76177628.

2. Oktay YILDIRIM, Preparation and Characterization of Chitosan/Calcium Phosphate Based Composite Biomaterials, Master Of Science Dissertation, zmir Institute of Technology zmir, Turkey. August, 2004

3. Muzzarelli RAA (1995) Chitin and the human body. In: First international Conference of the European Chitin Society. Advances in Chitin Science. Brest 448-461.

4. Jue-YL, Sung-HN, Su-YI, Yoon-JP, Yong-ML, et al. (2002) Enhanced bone formation by controlled growth factor delivery from chitosan-based biomaterials Journal of Controlled Release 78: 187-197.

5. Misiek DJ, Kent JN, Carr RF (1984) Soft tissue responses to hydroxylapatite particles of different shapes. J Oral Maxillofac Surg 42: 150-160.

6. Vert M, Li MS, Spenlehauer G, Guerin P (1992) Bioresorbability and biocompatibility of aliphatic polyesters. J Mater Sci 3: 432- 446

7. Hutmacher DW (2000) Scaffolds in tissue engineering bone and cartilage. Biomaterials 21: 2529-2543.

8. Henryk Pospieszny, Wojciech Folkman (2004) Factors modifying a biological activity of chitin derivatives. ed., Progress on Chemistry and Application of Chitin and its Derivatives, PT Chit 10: 7-12.

9. MH Fathi, A Hanifi, V Mortazavi (2008) Preparation and bioactivity evaluation of bone-like hydroxyapatite nanopowder, journal of materials processing technology 202: 536-542.

10. Soon-HK, Youn-KJ, Seong-HH, Hyoun-EK (2003) Synthesis and dissolution behavior of B-TCP and HA/B-TCP composite powder, Journal of European Ceramic Society 23: 1039-1045.

11. H Çigdem ARCA, Sevda S ENEL (2008) Chitosan Based Systems for Tissue Engineering Part 1: Hard Tissues, FABAD J Pharm Sci 33: 35-49.

12. J Klinkaewnarong, Ekaphan S, Santi MNanocrystalline (2009) hydroxyapatite powders by a chitosan-polymer complex solution route: Synthesis and characterization. Solid State Sciences 11: 1023-1027.

13. Riccardo AA Muzzarelli (2011) Chitosan composites with inorganics, morphogenetic proteins and stem cells, for bone regeneration. Carbohydrate Polymers 83: 1433-1445.

14. Majeti NV, Ravi Kumar (2000) A review of chitin and chitosan applications Reactive and Functional Polymers 46: 1-27.

15. Ding SJ (2006) Preparation and properties of chitosan/calcium phosphate composites for bone repair. Dent Mater J 25: 706-712.

16. Ratajska M, Haberko K, Cienchanska D, Niekraszewicz A, Kucharska M (2008) Hydroxiapatite-Chitosan $\mathrm{Bi}$ - ocomposites. Progress on Chemistry and Application of Chitin and Its Derivatives, PTChit 13: 89-94.

17. Bodek KH (2000) Evaluation of properties microcrystalline chitosan as a drug carrier. Part 1. In vitro release of diclofenac from mictocrystalline chitosan hydrogel. Acta Pol Pharm 57: 431-440. 
Citation: Pighinelli L, Guimaraes MF, Paz RL (2015) Properties of Hydrochloric Chitosan Solutions Modified With Nano-Calcium Phosphate Complex. J Tissue Sci Eng 6: 155. doi:10.4172/2157-7552.1000155

18. Wawro D, Pighinelli L (2011) Chitosan fibers modified with HAp/î²-TCP nanoparticles. Int J Mol Sci 12: 7286-7300

19. Skoog DA, Holler FJ, Nieman TA (2006) Principios de analise Instrumental, $5 a$ Ediçao, ed. Bookman, Brazil, 342-384

20. Liou SC, Chen SY (2002) Transformation mechanism of different chemically precipitated apatitic precursors into beta-tricalcium phosphate upon calcination. Biomaterials 23: 4541-4547.

21. Brugnerotto J, Lizardi FM, Goycoolea W, ArguĖelles-MJ, DesbrieÁres M, et al. (2001) An infrared investigation in relation with chitin and chitosan characterization. Polymer 42: 3569-3580.

22. Magdalena K, Antoni N, Maria WW, Ewa W, Henryk S (2003) Dressing Sponges
Made of Chitosan and Chitosan-Alginate Fibrids, ed, Progress on Chemistry and Application of Chitin and its Derivatives, PTChit 9: 69-72.

23. Rumi F, Atsuro Y, Yoshinobu N, Takao K, Takao K (2003) Ultrastructure of ceramic-bone interface using hydroxyapatite and B-tricalcium phosphate ceramics and replacement mechanism of B-tricalcium phosphate in bone. Tissue and Cell 35: 427-440.

24. Socratic D, Antonucci JM, Eanes ED (2003) Amorphous Calcium PhosphateBased Bioactive Polymeric Composites for Mineralised Tissue Regeneration. Journal of Research of the National Institute of Standards and Technology 108: 167-182.

25. Matsumoto T, Okazaki M, Inoue M, Hamada $Y$, Taira M, et al. (2002) Crystallinity and solubility characteristics of hydroxyapatite adsorbed amino acid. Biomaterials 23: 2241-2247. 